\title{
Changes in the inotropic state of the left ventricle during isometric exercise ${ }^{\mathrm{I}, 2}$
}

\author{
William Grossman, Lambert P. McLaurin, Stephen B. Saltz, John A. Paraskos ${ }^{3}$, \\ James E. Dalen, and Lewis Dexter \\ From the C. V. Richardson Cardiac Laboratory, North Carolina Memorial Hospital, and University of \\ North Carolina School of Medicine, Chapel Hill, N.C., and the Departments of Medicine, Peter Bent \\ Brigham Hospital, and Harvard Medical School, Boston, Massachusetts, U.S.A.
}

Left ventricular function during sustained isometric handgrip exercise was studied at the time of cardiac catheterization in 8 normal subjects and 26 patients with heart disease. Both groups showed increases in heart rate, aortic mean blood pressure, and cardiac minute output with no change in systemic vascular resistance.

Left ventricular filling pressure and stroke work were measured before and during isometric exercise in $I 7$ cases. In 7 normal subjects, stroke work increased $(8 I \pm 8 \cdot 8$ to I04 \pm II $g$ m, P<0.0I) without a significant change in left ventricular filling pressure $(6 \cdot 8 \pm 0.8$ to $7 \cdot 5 \pm I \cdot 2 \mathrm{mmHg}, \mathrm{NS})$ suggesting a shift to a higher ventricular function curve. Patients with heart disease, however, showed great variability in their stroke work response to isometric exercise ( 5 with increase, 3 with no change, and 2 with decrease), despite a significant increase in left ventricular filling pressure $(9.6 \pm 0.9 \mathrm{mmHg}$ to $15.5 \pm I .6 \mathrm{mmHg}, P<0.0 \mathrm{I})$.

Myocardial mechanics during isometric exercise were studied in 6 normal subjects and 8 patients with heart disease. Left ventricular pressure-velocity curves were shifted upwards and to the right in all 6 normal subjects and in 7 of the 8 patients with heart disease. Vmax (developed pressure) increased in both normal subjects $\left(74 \pm 6\right.$ to $\left.109 \pm 5 \mathrm{sec}^{-1},+47 \%, P<0.01\right)$ and to a lesser extent in the patients with heart disease $(59 \pm 8$ to $\left.82 \pm 12 \mathrm{sec}^{-1},+39 \%, P<0 \cdot 01\right)$ in response to isometric exercise. Similarly, maximum left ventricular $d p / d t$ increased in both normals (I88I $\pm I 63$ to $2408 \pm I 29 \mathrm{mmHg} / \mathrm{sec}, P<0 \cdot 0 \mathrm{I}$ ) and patients with heart disease ( $1540 \pm 140$ to $1976 \pm 24 \mathrm{ImmHg} / \mathrm{sec}, P<0 \cdot 0 \mathrm{I})$.

These observations suggest that the normal physiological response to isometric exertion includes a major increase in left ventricular myocardial contractility. For the normal heart, this increase appears sufficient to account completely for the increased ventricular performance associated with handgrip exercise. For the diseased heart, increased ventricular performance induced by handgrip appears also to be mediated by increased contractility, but in addition by varying degrees of reliance upon the Frank-Starling mechanism, depending upon the adequacy of inotropic (ccntractility) reserve to meet the stress imposed by isometric exercise.

In studies of the circulatory response to exercise, attention has been largely directed towards understanding the effects of dynamic exercise (Dexter et al., I95I). Recently, however, interest has focused on the cardiovascular effects of sustained voluntary muscle contraction, commonly termed isometric

Received 28 December 1972.

1 Supported in part by NIH Grants and by Grants-in-Aid from the North Carolina Heart Association.

${ }^{2} \mathrm{~A}$ preliminary report was presented at the annual meeting of the American Heart Association in Anaheim, California, Io November $197 \mathrm{I}$.

${ }^{3}$ Present address: Department of Medicine, Boston V. A. Hospital, Boston, Mass. 02115 , U.S.A. exercise, in both normal man and in patients with heart disease (Donald et al., 1967; Lind, 1970).

Lind and his colleagues (1964) and Lind (1970) have reported that sustained isometric contraction of the flexor muscles of the forearm elicits a cardiovascular reflex consisting of increases in heart rate, arterial blood pressure, and cardiac output. The resultant stress on cardiac performance has been utilized by several groups (Helfant, de Villa, and Meister, I971; Siegel et al., 1972) as an aid in the evaluation of cardiac function in general, and left ventricular reserve in particular.

Despite this recent upsurge in interest, the details 
of the normal physiological response to isometric exercise remain uncertain. The mechanism by which enhanced left ventricular performance is accomplished and, in particular, the role played by changes in inotropic state of the left ventricular myocardium during isometric exercise, needs clarification.

This study was undertaken to investigate these physiological details, and to delineate the mechanism of the left ventricular response to the stress of isometric exercise.

\section{Methods}

The cardiovascular response to isometric handgrip was evaluated in 34 patients undergoing routine diagnostic cardiac catheterization.

Eight patients (Table I) were found to be essentially normal at the time of cardiac catheterization. The indications for catheterization in these patients included chest pain of uncertain aetiology in 5 patients (coronary arteriography showed no abnormality); suspected congenital aortic stenosis (not found) in I patient, and suspected left heart failure (not found) in 2 patients with chronic lung disease.

Twenty-six patients were found to have various types of heart disease, and characteristics of individual patients in this group are summarized in Table 2.

Isometric handgrip exercise was performed by each patient using a handgrip dynamometer, consisting of an inflated pneumatic cuff attached to a blood pressure gauge in 30 patients, and a Jamar adjustable dynamometer $^{1}$ in 4 patients. The patient's maximum voluntary contraction was determined, and subsequently the patient was asked to grasp the dynamometer at a tension sufficient to maintain the gauge needle at 50 per cent maximum voluntary contraction for 3 minutes. Patients were instructed not to perform a Valsalva manoeuvre ${ }^{1}$ Asimow Engineering Company, Los Angeles, California. during the exercise period, and careful observation of their respiratory pattern was maintained during and at I, 2, and 3 minutes after the onset of handgrip exercise.

\section{Pressures}

Brachial artery pressure was measured in all patients through a PEI60 indwelling polyethylene catheter inserted percutaneously into the brachial artery. Left ventricular end-diastolic pressure (3I patients) and pulmonary capillary wedge pressure (2 patients) were measured through standard catheters attached to Statham pressure transducers. In 14 patients high fidelity left ventricular pressure tracings were obtained using micromanometer tipped catheters (Telco, ${ }^{1}$ SF-r,${ }^{2}$ or Mikro-tip ${ }^{3}$ ) and only these tracings were used for studies of myocardial mechanics.

\section{Outputs}

Cardiac output was determined at rest and during handgrip by the indicator dilution technique. Indocyanine green dye was injected in the main pulmonary artery 2 minutes and 30 seconds after onset of handgrip and was sampled from the brachial artery. Dye concentration was detected by a Gilford densitometer, and cardiac outputs were computed using a Lexington cardiac output computer. Stroke work was computed in $\mathrm{g} \mathrm{m}$ as

(Aortic mean pressure, $\mathrm{mmHg}$-LVEDP, $\mathrm{mmHg}$ )

$(\mathrm{SV}, \mathrm{ml}) \mathrm{I} \cdot 36$

100

where LVEDP is left ventricular end-diastolic pressure. When aortic regurgitation was present, left ventricular systolic mean was used instead of aortic mean pressure.

Systemic vascular resistance (dynes-sec- $\mathrm{cm}^{-5}$ ) was

${ }^{1}$ Telco MSD8 micromanometer, Carolina Medical Electtronics, King, North Carolina.

${ }^{2}$ SF-I micromanometer, Statham Laboratories, Hato Rey, Puerto Rico.

${ }^{3}$ Millar Instruments, Houston, Texas.

TABLE I Haemodynamic observations during isometric handgrip in normal subjects

\begin{tabular}{|c|c|c|c|c|c|c|c|c|c|c|}
\hline \multirow[t]{2}{*}{ Case No. } & \multirow[t]{2}{*}{ Age } & \multirow[t]{2}{*}{ Sex } & \multicolumn{2}{|c|}{$\begin{array}{l}\text { Heart rate } \\
\text { (beats } / \text { min) }\end{array}$} & \multicolumn{2}{|c|}{$\begin{array}{l}\text { Aortic mean pressure } \\
(\mathrm{mmHg})\end{array}$} & \multicolumn{2}{|c|}{$\begin{array}{l}\text { Stroke volume } \\
\text { (ml/beat) }\end{array}$} & \multicolumn{2}{|c|}{$\begin{array}{l}\text { Stroke work } \\
(g \mathrm{~m})\end{array}$} \\
\hline & & & $C$ & $E x$ & $C$ & $E x$ & $C$ & $E x$ & $C$ & $E x$ \\
\hline I & 48 & $M$ & 52 & 64 & 90 & IIO & 94 & 94 & 105 & 130 \\
\hline 2 & 46 & $\mathbf{M}$ & 69 & 90 & 100 & I43 & 83 & 72 & 113 & 140 \\
\hline 3 & 35 & $\mathrm{~F}$ & 96 & I26 & 84 & IIO & 42 & 40 & 46 & 59 \\
\hline 4 & 32 & $\mathbf{M}$ & 84 & 98 & 100 & 130 & 67 & 65 & 82 & 104 \\
\hline 5 & 72 & $\mathbf{M}$ & 90 & 102 & 94 & 106 & 71 & 91 & 86 & 124 \\
\hline 6 & 20 & $\mathbf{M}$ & 78 & 130 & 86 & II 2 & 62 & 65 & 66 & 94 \\
\hline \multirow{4}{*}{$\begin{array}{l}7 \\
8\end{array}$} & 65 & $\mathrm{~F}$ & 72 & 84 & IIO & 138 & 47 & 42 & 66 & 79 \\
\hline & 57 & $\mathrm{~F}$ & 90 & 90 & 90 & 102 & - & - & - & - \\
\hline & \multirow{2}{*}{\multicolumn{2}{|c|}{$\begin{array}{l}\text { Mean } \\
\pm \text { SEM }\end{array}$}} & $\begin{array}{l}79 \\
\pm 5\end{array}$ & $\begin{array}{r}98 \\
\pm 8\end{array}$ & $\begin{array}{r}94 \\
\pm 3\end{array}$ & $\begin{array}{l}119 \\
\pm 5.5\end{array}$ & $\begin{array}{c}66 \cdot 5 \\
\pm 7\end{array}$ & $\begin{array}{l}67 \\
\pm 8\end{array}$ & $\begin{array}{c}8 \mathrm{I} \\
\pm 8.8\end{array}$ & $\begin{array}{l}\text { IO4 } \\
\pm \text { II }\end{array}$ \\
\hline & & & & & & & & & & \\
\hline
\end{tabular}

Abbreviations: SVR, systemic vascular resistance; $V \max (\mathrm{DP}), \mathrm{Vmax}$ measured with developed pressure (see text); $\mathrm{dP} / \mathrm{dt}$, maximum rate of rise of left ventricular pressure; SEM, standard error of the mean; PEP/LVET, see text; C, control; Ex, during third minute of exercise; NS, difference not statistically significant; LVEDP, left ventricular end-diastolic pressure.

* Statistics not done because of small number of observations. 
calculated as aortic mean pressure $(\mathrm{mmHg}) \times 1332$ cardiac output (ml/sec).

\section{Myocardial mechanics}

These were studied in 14 patients using high-fidelity left ventricular pressure signals as the input to a logarithmic amplifier circuit previously described (Grossman et al., I97I), to yield on-line measures of $(\mathrm{dP} / \mathrm{dt}) / \mathrm{P}$, and pressure-velocity plots of $(\mathrm{dP} / \mathrm{dt}) / \mathrm{P}$ on the ordinate against $\mathbf{P}$ on the abscissa. A voltage clamp device was used to obtain 'developed' left ventricular pressure, as described by Urschel, Henderson, and Sonnenblick (1970) and Grossman et al. (1972), as the input to the log amplifier circuit.

Measurements specifically examined included: (a) maximum $\mathrm{dP} / \mathrm{dt}$, as determined with total pressure, and (b) Vmax determined using developed left ventricular pressure. Determination of $V \max$ from phase plots of $(\mathrm{dP} / \mathrm{dt}) / \mathbf{P}$ vs $\mathbf{P}$ using developed pressure was made as follows. Though phase plots of $(\mathrm{dP} / \mathrm{dt}) / \mathrm{P}$ on the ordinate against $\mathbf{P}$ on the abscissa were generally inverse curvilinear, the shape of such curves varied from a nearly linear inverse relation to a shallow concave upward curve. For this reason, we have followed the technique of Wolk and his colleagues (197I) and Mason, Spann, and Zelis (1970) whereby extrapolation of the curve to the velocity axis intercept (Vmax) was accomplished by hand and consisted of a smooth extension of the best line drawn through the inverse portion of the curves beyond $P=10$ $\mathrm{mmHg}$, following the approach of Urschel et al. (1970) who have pointed out that only at pressures above $\mathrm{P}=$ Io $\mathrm{mmHg}$ can the $\mathrm{C}$ constant (in the equation $\mathrm{V}_{\mathrm{ce}}=(\mathrm{dP} / \mathrm{dt}) /(\mathrm{KP}+\mathrm{C})$ be neglected. Though some authors perform the extrapolation to Vmax mathematically, using the Hill equation, recent experiments (Noble,

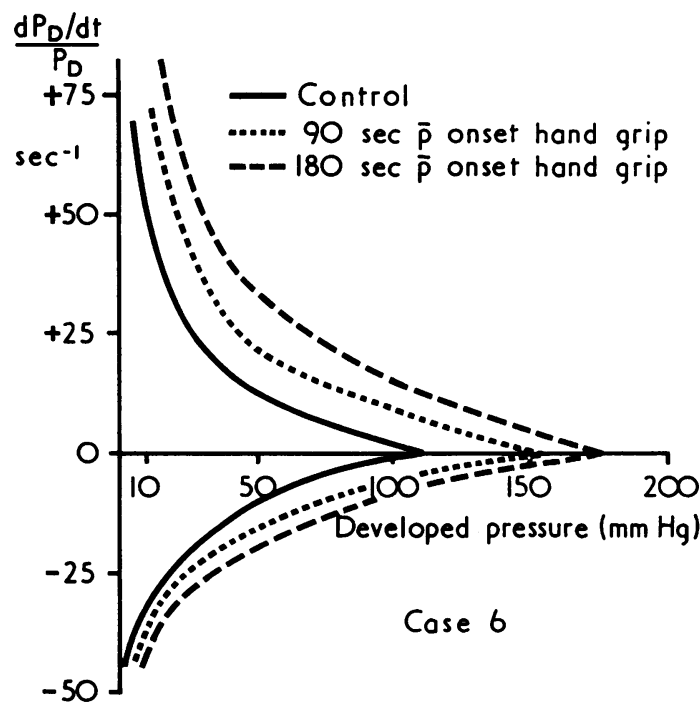

FIG. I Response of the left ventricular pressurevelocity phase plot to isometric exercise in a normal subject.

$(d P / d t) / P$, using developed pressure, is plotted on the ordinate against developed left ventricular pressure on the abscissa in the control state and at 90 and 180 seconds after the onset of isometric exercise. Note that curves are shifted upwards and to the right, indicating an increase in left ventricular myocardial contractility. Curves represent direct tracings from experimental records obtained using a logarithmic amplifier technique previously described (Grossman et al., 1971).

\begin{tabular}{|c|c|c|c|c|c|c|c|c|c|}
\hline \multicolumn{2}{|c|}{$L V E D P(m m H g)$} & \multicolumn{2}{|c|}{$S V R$ dynes-sec-cm -5} & \multicolumn{4}{|c|}{ Left ventricular pressure } & \multicolumn{2}{|c|}{$P E P / L V E T$} \\
\hline \multirow[b]{2}{*}{$C$} & \multirow[b]{2}{*}{$E x$} & \multirow[b]{2}{*}{$C$} & \multirow[b]{2}{*}{$E x$} & \multicolumn{2}{|c|}{$V \max (D P) \sec ^{-1}$} & \multicolumn{2}{|c|}{$d P / d t \mathrm{mmHg} / \mathrm{sec}$} & \multirow[b]{2}{*}{$C$} & \multirow[b]{2}{*}{$E x$} \\
\hline & & & & $C$ & $E x$ & $C$ & $E x$ & & \\
\hline 8 & 8 & 1470 & 1480 & 87 & 122 & 1798 & 2188 & - & - \\
\hline 9 & 12 & 1330 & 1860 & 86 & 100 & I876 & 2500 & 一 & 一 \\
\hline 4 & 2 & 1666 & I746 & - & - & - & - & 0.464 & 0.438 \\
\hline 10 & 12 & I 574 & I 457 & 64 & 96 & 1600 & 2080 & - & - \\
\hline 5 & 6 & I777 & 914 & - & - & - & - & 0.520 & 0.440 \\
\hline $7 \cdot 5$ & 6 & 1423 & 1060 & 50 & 121 & 1638 & 2457 & - & - \\
\hline 6 & 7 & 2600 & 3000 & 81 & 99 & 2500 & 2816 & - & - \\
\hline 5 & 7 & - & - & 77 & 118 & - & - & 一 & 一 \\
\hline $\begin{array}{r}6.8 \\
+0.8\end{array}$ & $\begin{array}{r}7.5 \\
\pm 1.2\end{array}$ & $\begin{array}{r}1606 \\
\pm 176\end{array}$ & $\begin{array}{r}1645 \\
\pm 260\end{array}$ & $\begin{array}{r}74 \\
\pm 6\end{array}$ & $\begin{array}{l}109 \\
\pm 5\end{array}$ & $\begin{array}{r}1881 \\
\pm 163\end{array}$ & $\begin{array}{r}2408 \\
\pm 129\end{array}$ & 0.492 & $\underline{0.439}$ \\
\hline \multicolumn{2}{|c|}{ NS } & \multicolumn{2}{|c|}{ NS } & \multicolumn{2}{|c|}{$<0.01$} & \multicolumn{2}{|c|}{$<0.01$} & \multicolumn{2}{|l|}{ 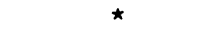 } \\
\hline
\end{tabular}


Bowen, and Hefner, 1969) have cast doubt upon the applicability of this equation to heart muscle. No series elastic constant $(K)$ was used (that is, $K$ was arbitrarily set equal to $\mathrm{I}$ ) since the value of $\mathrm{K}$ is unknown in man, and values of Vmax are correspondingly reported in $\mathrm{sec}^{-1}$, rather than muscle lengths/sec.

Systolic time intervals, in particular the ratio of the pre-ejection period to the left ventricular ejection time (PEP/LVET), were studied in 8 patients using direct measurements from aortic and left ventricular pressure tracings, and lead II of the electrocardiogram. The preejection period was taken as the time from the onset of the QRS complex of the electrocardiogram to the upstroke of the aortic pressure tracing. Left ventricular ejection time was taken from aortic pressure tracings as the time from onset of upstroke to the dicrotic notch. Pre-ejection period as measured by this technique was not corrected for catheter delay time, and therefore the absolute values for pre-ejection time to left ventricular ejection time as reported in this study are larger than the true values. The intent of this part of the study was to examine changes (rather than absolute values) in systolic time intervals during isometric exercise.

Pressure and output data were analysed in terms of a ventricular function plot with stroke work plotted on the ordinate against left ventricular end-diastolic pressure on the abscissa in ro patients.

Data were analysed using the t-test for paired data, and differences with $\mathrm{P}<0.05$ were considered significant.

\section{Results}

\section{Haemodynamics}

A. Normal subjects Eight patients were found to be essentially normal ${ }^{1}$ at the time of cardiac

1 See Methods for details.

Abbreviations are as in Table $\mathrm{I}$.

$\star \mathbf{P}<0.01$.

+ Cases 10, 12, 13, 13, 24, 26, and 28-31 were in atrial fibrillation. All other patients were in normal sinus rhythm. $\ddagger$ Pulmonary capillary wedge pressure; all other values represent left ventricular end-diastolic pressure.

NS, difference is not statistically significant. 
catheterization. In this group (Table I) aortic mean pressure increased in all patients $(94 \pm 3 \mathrm{mmHg}$ to I $19 \pm 5.5 \mathrm{mmHg}$, mean \pm standard error, $P<0.00 \mathrm{r}$ ), and heart rate increased in 7 of 8 (for the group of 8 patients, $79 \pm 5$ to $98 \pm 8$ beats $/ \mathrm{min}, P<0.01$ ) in response to isometric handgrip. All were in normal sinus rhythm. Left ventricular end-diastolic pressure was unchanged $(6.8 \pm 0.9$ to $7.5 \pm \mathrm{I} \cdot 2 \mathrm{mmHg}$, NS) with handgrip, while stroke work increased $(8 \mathrm{I} \pm 8.8$ to $104 \pm \mathrm{II} \mathrm{g} \mathrm{m}, \mathrm{P}<0.00 \mathrm{I})$, consistent with a shift to a higher ventricular function curve.

Systemic vascular resistance was essentially unchanged ( $1606 \pm 176$ to $1645 \pm 260$ dynes-sec- $\mathrm{cm}^{-5}$, NS) in the normal subjects during isometric handgrip, while cardiac output (product of heart rate and stroke volume) increased $(4.9 \pm 0.4 \mathrm{l} / \mathrm{min}$ to $6.4 \pm 0.7 \mathrm{l} . / \mathrm{min}, P=0.02)$.
Patients with heart disease Twenty-six patients with various forms of heart disease were studied and the results are presented in Table 2 . As can be seen, both aortic mean pressure and heart rate increased with isometric handgrip, and the increases were quite similar in magnitude to those seen in the group of normal patients.

In contrast to the responses observed in the normal group, however, left ventricular filling pressure rose significantly with handgrip in the group of 26 patients with heart disease $(9.6 \pm 0.9 \mathrm{mmHg}$ to $15.5 \pm 1.6 \mathrm{mmHg}, P<0.01$ ), as well as in the various subdivisions of this group reported in Table 2 ( 5 patients with coronary artery disease, Io patients with mitral valve disease, 3 patients with aortic valve disease, 4 patients with mixed aortic and mitral disease, and I patient each with cardiomyo-

\begin{tabular}{|c|c|c|c|c|c|c|c|c|c|c|c|}
\hline \multirow{2}{*}{\multicolumn{2}{|c|}{ Stroke work ( $(\mathrm{m})$}} & \multirow{2}{*}{\multicolumn{2}{|c|}{$L V E D P(m m H g)$}} & \multirow{2}{*}{\multicolumn{2}{|c|}{$\begin{array}{l}\text { SVR } \\
\text { dynes-sec-cm-5 }\end{array}$}} & \multicolumn{4}{|c|}{ Left ventricular pressure } & \multirow{2}{*}{\multicolumn{2}{|c|}{$P E P / L V E T$}} \\
\hline & & & & & & \multicolumn{2}{|c|}{$V \max (D P) \sec ^{-1}$} & \multicolumn{2}{|c|}{$d P / d t \mathrm{mmHg} / \mathrm{sec}$} & & \\
\hline$C$ & $E x$ & $C$ & $E x$ & $C$ & $E x$ & $C$ & $E x$ & $C$ & $E x$ & $C$ & $E x$ \\
\hline 一 & - & 6 & 8 & - & - & - & 一 & - & 一 & - & - \\
\hline 一 & - & 9 & $2 \mathrm{I}$ & - & - & - & - & 1000 & 1000 & - & - \\
\hline - & - & 8 & 10 & - & - & 87 & 103 & 2285 & 3660 & - & 一 \\
\hline - & 一 & 5 & $7 \cdot 5$ & 一 & 一 & 46 & 59 & 2190 & 2670 & - & - \\
\hline 一 & - & 12 & 14 & - & - & 一 & 一 & 一 & 一 & - & 一 \\
\hline 54 & 94 & 17 & 34 & 2006 & 2052 & - & 一 & - & 一 & - & - \\
\hline- & - & 7 & Io & - & - & - & - & - & - & - & - \\
\hline 55 & 49 & 4 & 6 & 1626 & 1643 & 76 & II2 & - & - & 0.260 & 0.238 \\
\hline- & - & 6 & 10 & - & - & 64 & 97 & - & - & - & - \\
\hline 68 & 4I & 15 & 22 & 1475 & 3190 & 99 & 130 & 1650 & 2010 & - & - \\
\hline 89 & 102 & 8 & IO & 1377 & 1333 & - & - & - & - & 0.239 & 0.220 \\
\hline- & - & 14 & 18 & - & - & - & - & - & - & - & 一 \\
\hline 47 & 84 & II & 13 & $208 I$ & 1557 & 82 & 124 & 1830 & 2080 & 0.440 & 0.290 \\
\hline 49 & 49 & 8 & 18 & 1662 & 2702 & I8 & 19 & 1155 & 1380 & 0.198 & 0.246 \\
\hline 56 & 65 & 9 & I0 & 2222 & 2644 & - & - & - & - & 0.187 & 0.254 \\
\hline - & - & I7 & 28 & - & - & - & - & - & - & - & - \\
\hline - & - & 4 & 6 & 一 & - & - & - & 1310 & I960 & - & - \\
\hline 24 & 32 & $15 \ddagger$ & 20 & 2576 & 2404 & - & - & - & - & - & - \\
\hline- & - & 7 & 9 & - & - & - & - & I 147 & 1260 & - & - \\
\hline - & - & 4 & 30 & - & - & - & - & 1460 & 2020 & - & - \\
\hline 50 & 96 & 12 & 20 & 2089 & 1042 & - & - & - & - & - & - \\
\hline$\overline{-}$ & - & - & - & - & - & - & - & - & - & - & - \\
\hline 54 & 46 & 15 & 24 & I706 & I977 & - & - & - & - & - & - \\
\hline - & - & $14 \ddagger$ & $2 I$ & - & - & - & - & - & - & - & 一 \\
\hline - & - & 8 & 13 & - & - & 48 & 71 & 1370 & 1720 & 0.665 & 0.500 \\
\hline- & - & 6 & 6 & - & - & - & - & - & - & - & - \\
\hline $\begin{array}{l}55 \\
\pm 5 \cdot 1\end{array}$ & $\begin{array}{c}66 \\
\pm 8 \cdot 2\end{array}$ & $\begin{array}{r}9.6 \\
\pm 0.9\end{array}$ & $\begin{array}{r}15.5 \\
\pm 1.6\end{array}$ & $\begin{array}{r}1882 \\
\pm 118\end{array}$ & $\begin{array}{r}2054 \\
\pm 215\end{array}$ & $\begin{array}{r}59 \\
\pm 8\end{array}$ & $\begin{array}{r}82 \\
\pm 12\end{array}$ & $\begin{array}{r}1540 \\
\pm 140\end{array}$ & $\begin{array}{r}1976 \\
\pm 241\end{array}$ & $\begin{array}{r}0.332 \\
\pm 0.076 \\
(\mathrm{~N}\end{array}$ & $s)^{ \pm 0.043}$ \\
\hline
\end{tabular}


pathy, restrictive disease, hypertension, and persistent ductus arteriosus). In addition, in contrast to the findings in the normal group, stroke work for the entire group of patients with heart disease showed no significant change, reflecting a wide variation in individual responses, as described in detail below.

Finally, as with the normal group, systemic vascular resistance showed no overall change for the Io patients with heart disease in whom it was measured (1882 \pm 118 dynes-sec- $\mathrm{cm}^{-5}$ to $2054 \pm 215$ dynessec- $\mathrm{cm}^{-5}, \mathrm{NS}$ ), while cardiac output increased for the group of 10 patients from $4.1 \pm 0.31 . / \mathrm{min}$ to $4.9 \pm 0.61 . / \mathrm{min}$. The increase in cardiac output was not statistically significant, reflecting the fact that in 2 patients (Cases 18 and 22, Table 2) with massive valvular regurgitation, effective or forward cardiac outputs fell in response to the exercise stress, while systemic vascular resistance rose.

\section{Myocardial mechanics}

Both Vmax (using developed pressure) and maximum left ventricular $\mathrm{dP} / \mathrm{dt}$ showed significant increases during isometric handgrip in normals, with Vmax rising from $74 \pm 6 \mathrm{sec}^{-1}$ to $109 \pm 5 \mathrm{sec}^{-1}$, $\mathrm{P}<0.01$, and $\mathrm{dP} / \mathrm{dt}$ rising from $188 \mathrm{I} \pm 163 \mathrm{mmHg} /$ sec to $2408 \pm 129 \mathrm{mmHg} / \mathrm{sec}, \mathrm{P}<0.01$. In patients with heart disease, increases in $V \max \left(59 \pm 8 \mathrm{sec}^{-1}\right.$ to $\left.82 \pm \mathrm{I} 2 \mathrm{sec}^{-1}, \mathrm{P}<0.0 \mathrm{I}\right)$ and maximum left ventricular $\mathrm{dP} / \mathrm{dt}(\mathrm{I} 540 \pm 140$ to $1976 \pm 24 \mathrm{I}, \mathrm{P}<0.0 \mathrm{I})$ were also seen, though the resting and peak values were of smaller magnitude than in the normal group. Pressure-velocity phase plots (with $[\mathrm{dP} / \mathrm{dt}] / \mathbf{P}$ on the ordinate against $P$ on the abscissa, using developed pressure) shifted upwards and to the right during handgrip in both groups. An example of this for one of the normal subjects is shown in Fig. I. These results were consistent with an increase in contractile state of the left ventricle in response to isometric exercise.

\section{Ventricular function plots}

When changes in left ventricular filling pressure were plotted on the abscissa against changes in stroke work on the ordinate, an interesting relation became apparent (Fig. 2). The 7 normal subjects showed a large increase in stroke work without any significant increase in left ventricular filling pressure, suggesting an increase in myocardial contractility. In contrast, patients with heart disease (shown individually in Fig. 2) showed a highly variable response to isometric handgrip, suggesting movement either on the ascending portion, plateau segment, or descending limb of the ventricular function curve. It should be emphasized that the patients

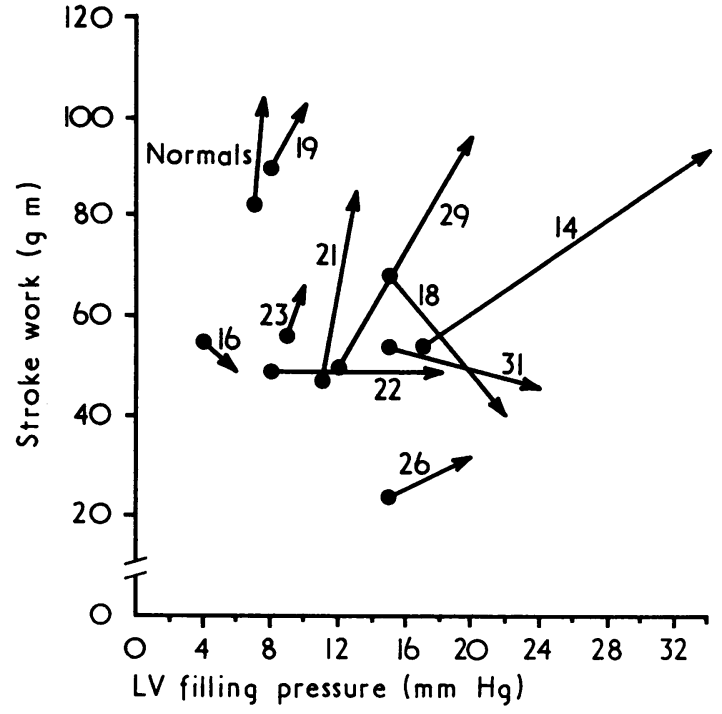

FIG. 2 Ventricular function plots illustrating the response to isometric exercise in normals and patients with various forms of heart disease.

Each arrow represents the values of $L V$ filling pressure and stroke work in the control state (solid dots) and during isometric exercise (arrow heads). The arrow marked 'normals' represents mean control and exercise values for the normal group. The other arrows show control and exercise values for individual patients (identified by their case numbers) with various forms of heart disease as detailed in Table 2.

with heart disease represent a mixed group, having varying degrees of impaired left ventricular function depending on the nature and severity of their specific type of heart disease (cf. Table 2).

\section{Systolic time intervals}

The PEP/LVET ratio, proposed by Weissler, Harris, and Schoenfeld (1969) as an inverse index of myocardial performance, decreased during handgrip in both normal subjects in whom it was measured (Table I), consistent with an increase in left ventricular myocardial contractility. In the patients with heart disease (Table 2) PEP/LVET decreased in 4 patients to a similar extent as seen in the normal subjects, but in 2 patients with severe mixed aortic and mitral regurgitation, PEP/LVET increased during handgrip. Concomitant studies of myocardial mechanics in one of these two patients (Case 22) showed no increase in Vmax (developed pressure), and this was the only patient we have studied in whom Vmax failed to increase with handgrip. These data are consistent with the hypothesis that PEP/ LVET normally decreases in response to isometric 
handgrip exercise, except in patients who lack inotropic reserve.

\section{Discussion}

The observations of this study suggest the hypothesis that the normal cardiovascular response to isometric exertion includes a major increase in left ventricular myocardial contractility. Consistent with this hypothesis are the findings that during isometric exercise (a) Vmax (developed pressure) and pressure-velocity curves obtained from left ventricular pressure tracings consistently show changes indicative of an increase in myocardial contractility; (b) increases in cardiac output and stroke work occur, in normals at least, without any increase in left ventricular filling pressure, suggesting a shift to a higher contractile state, and (c) increases in aortic pressure appear to be accomplished in normals and most patients with heart disease by an increase in cardiac output, with no significant change in systemic vascular resistance. This hypothesis is consistent with data previously presented by ourselves (Saltz et al., 197I) and others (Krayenbuehl et al., 1972; Siegel et al., 1972).

The mechanisms by which this augmentation in the contractile state of the left ventricular myocardium might occur are unclear at the present time. Increases in heart rate alone may have a positive inotropic effect, but Case 8 (Table I) and Cases 17 , 21 , and 33 (Table 2) showed definite increases in Vmax (developed pressure) without significant change in heart rate, implying the operation of some other factor. Recently Freyschuss (I970a, b) has examined the role of autonomic reflex mechanisms in the blood pressure and heart rate responses to brief (3-8 seconds) periods of isometric exercise. Those studies suggested that withdrawal of vagal tone was implicated rather than an increase in sympathetic drive after the onset of isometric exercise. Whether the same physiological mechanisms apply to the blood pressure, heart rate, and left ventricular contractility alterations observed with the sustained ( 3 minutes) isometric exercise examined in the present study, must await further investigation.

The physiological response to isometric exercise in patients with heart disease was similar in several respects to the response seen in normals. Both groups showed significant increases in heart rate and aortic mean pressure, and similar directional changes (though of lesser magnitude) in cardiac output and Vmax. For both groups there was no significant change in systemic vascular resistance. However, it is important to note certain instructive differences between the two groups. First, though stroke work increased in normal subjects and in most patients with heart disease, this increase was associated with a significant rise in left ventricular filling pressure only for the heart disease group. The performance of increased stroke work without an increase of left ventricular filling pressure by the normal heart defines an increase in ventricular function accomplished by calling on inotropic (contractility) reserve, without using the Frank-Starling mechanism. In order to accomplish this same increase in ventricular performance, patients with heart disease also called upon their inotropic reserve (as evidenced by increases in Vmax), but in addition used the FrankStarling mechanism to a varying extent, depending on the adequacy of inotropic reserve to meet the stress imposed by isometric exercise. Though this explanation seems to explain best the stroke workventricular filling pressure relation observed in the present study, it should be pointed out that a change in diastolic compliance of the left ventricle somehow induced by isometric exercise could explain these observations equally well. We have not examined this possibility experimentally, and therefore cannot comment upon it further.

The observation that systemic vascular resistance showed no overall change in response to isometric exercise either for the normal subjects or the patients with heart disease confirms the findings of Donald et al. (1967), and suggests that the consistent increases noted in aortic blood pressure in response to isometric exercise are secondary to increases in cardiac minute output. While the augmented minute output may reflect a composite of influences, it seems probable that increased left ventricular myocardial contractility is playing a major role.

Alterations in systolic time intervals observed during isometric exercise in the present study were consistent with the proposed physiological mechanism of increased inotropic drive. Weissler et al. (1969) have proposed the PEP/LVET ratio as an index of left ventricular myocardial performance and have noted that congestive heart failure is, in general, associated with an increase in PEP/LVET, while administration of positive inotropic agents such as isoprenaline or the digitalis glycosides results in a fall in PEP/LVET. In the present study PEP/LVET fell in response to handgrip in both normal subjects and in 4 out of 6 patients with heart disease in whom it was measured. The small number of observations here precluded speculation about the usefulness of PEP/LVET measurements during handgrip in detecting patients with diminished myocardial reserve. It should be noted that the preejection period in our study was uncorrected for catheter delay, so that absolute or true values for it and for PEP/LVET would be lower than measured, though directional changes and their magnitudes 
should be unaffected since the same catheter delay characterized both resting and exercise measurements.

One clinical implication of this study is the possible danger of isometric exercise for patients with coronary heart disease. Though not measured in our patients, it can be predicted that myocardial oxygen consumption increased greatly in response to handgrip, since each of its prime determinants (namely inotropic state, heart rate, and aortic pressure) was increased. A major increase in myocardial oxygen demand in association with the limited potential for increasing coronary flow seen in patients with coronary atherosclerosis should predispose to ischaemia, and may account for the increased incidence of ventricular arrhythmias with isometric handgrip reported by Atkins et al. (1971). Until more is known about these potential hazards of isometric exercise, its role as an aid to clinical testing, as well as a technique for achieving physical fitness, remains uncertain.

\section{References}

Atkins, J. M., Matthews, O. A., Houston, J. D., Blomqvist, G., and Mullins, C. B. (1971). Arrhythmias induced by isometric exercise and dynamic exercise (abstract). Clinical Research, 19, 303.

Dexter, L., Whittenberger, J. L., Haynes, F. W., Goodale, W. T., Gorlin, R., and Sawyer, C. G. (195I). Effect of exercise on circulatory dynamics of normal individuals. fournal of Applied Physiology, 3, 439.

Donald, K. W., Lind, A. R., McNicol, G. W., Humphreys, P. W., Taylor, S. H., and Staunton, H. P. (1967). Cardiovascular responses to sustained (static) contractions. Circulation Research, 20 and 21, Suppl. I, 15.

Freyschuss, U. (1970a). Cardiovascular adjustment to somatomotor activation. Acta Physiologica Scandinavica, Suppl. 342.

Freyschuss, U. (1970b). Elicitation of heart rate and blood pressure increase on muscle contraction. Fournal of Applied Physiology, 28, 758.

Grossman, W., Brooks, H. L., Meister, S. G., Sherman, IH., and Dexter, L. (197I). New technique for determining instantaneous myocardial force-velocity relations in the intact heart. Circulation Research, 28, 290.

Grossman, W., Haynes, F., Paraskos, J. A., Saltz, S., Dalen J. E., and Dexter, L. (1972). Alterations in preload and myocardial mechanics in the dog and in man. Circulation Research, 31, 83.

Helfant, R. H., deVilla, M. A., and Meister, S. G. (197I) Effect of sustained isometric handgrip exercise on left ventricular performance. Circulation, 44, 982.

Krayenbuehl, H. P., Rutishauser, W., Schoenbeck, M., and Amende, I. (1972). Evaluation of left ventricular function from isovolumic pressure measurements during isometric exercise. American fournal of Cardiology, 29, 323.

Lind, A. R. (1970). Editorial. Cardiovascular responses to static exercise (isometrics, anyone ?). Circulation, 4I, 173

Lind, A. R., Taylor, S. H., Humphreys, P. W., Kennelly, B. M., and Donald, K. W. (1964). Circulatory effects of sustained voluntary muscle contraction. Clinical Science, 27, 229.

Mason, D. T., Spann, J. F., and Zelis, R. (1970). Quantification of the contractile state of the intact human heart. American fournal of Cardiology, 26, 248.

Noble, M. I. M., Bowen, T. E., and Hefner, L. L. (1969). Force-velocity relationship of cat cardiac muscle, studied by isotonic and quick-release techniques. Circulation Research, 24, 82I.

Saltz, S., Grossman, W., Paraskos, J., Segal, H., Dalen, J. E., and Dexter, L. (197I). Left ventricular function: response to sustained isometric handgrip (abstract). Circulation, 46, II-63.

Siegel, W., Gilbert, C. A., Nutter, D. O., Schlant, R. O., and Hurst, J. W. (1972). Use of isometric handgrip for the indirect assessment of left ventricular function in patients with coronary atherosclerotic heart disease. American Fournal of Cardiology, 30, 48.

Urschel, C. W., Henderson, A. H., and Sonnenblick, E. H. (1970). Model dependency of ventricular force-velocity relations: importance of developed pressure (abstract). Federation Proceedings, 29, 719.

Weissler, A. M., Harris, W. S., and Schoenfeld, C. D. (1969). Bedside technics for the evaluation of ventricular function in man. American fournal of Cardiology, 23, 577.

Wolk, M. J., Keefe, J. F., Bing, O. H. L., Finkelstein, L. J., and Levine, H. J. (I971). Estimation of Vmax in auxotonic systoles from the rate of relative increase of isovolumic pressure: (dP/dt)/KP. Fournal of Clinical Investigation, 50, I276.

Requests for reprints to Dr. William Grossman, Department of Medicine, University of North Carolina, School of Medicine, Chapel Hill, North Carolina 275r4, U.S.A. 